\title{
Formulation and In-Vitro Evaluation of Meloxicam Solid Dispersion using Natural Polymers.
} Hiba R. Al-Hassani", ${ }^{* 1}$ and Eman B. H. Al-Khedairy*

*Ministry of Health and Environment, Baghdad, Iraq. *Department of Pharmaceutics College of Pharmacy, University of Baghdad, Baghdad, Iraq.

\section{Abstract}

Meloxicam (MLX) is non-steroidal anti-inflammatory, poorly water soluble, highly permeable drug and the rate of its oral absorption is often controlled by the dissolution rate in the gastrointestinal tract. Solid dispersion (SD) is an effective technique for enhancing the solubility and dissolution rate of such drug.

The present study aims to enhance the solubility and the dissolution rate of MLX by SD technique by solvent evaporation method using sodium alginate (SA), hyaluronic acid (HA), collagen and xyloglucan (XG) as hydrophilic natural polymers.

Twelve formulas were prepared in different drug: polymer ratios and evaluated for their, percentage yield, drug content, water solubility, dissolution rate, crystal lattice using powder X-ray diffraction (PXRD) and Fourier Transform Infrared Spectroscopy (FTIR) for determination the drug-polymer interaction.

All the prepared formulas showed improvement of drug solubility except that prepared with HA. The best result was obtained with formula SD1 (MLX: SA 1:1) that showed a high percentage yield (97\%), high drug content $(97.4 \pm 0.05 \%)$ and increase in solubility compared to solubility of pure MLX with improved dissolution rate. The PXRD study revealed the conversion of the drug to amorphous form without chemical interaction according to FTIR results

Keywords: Meloxicam, Solid dispersions, Sodium alginate, Hyaluronic acid, Collagen, Xyloglucan.

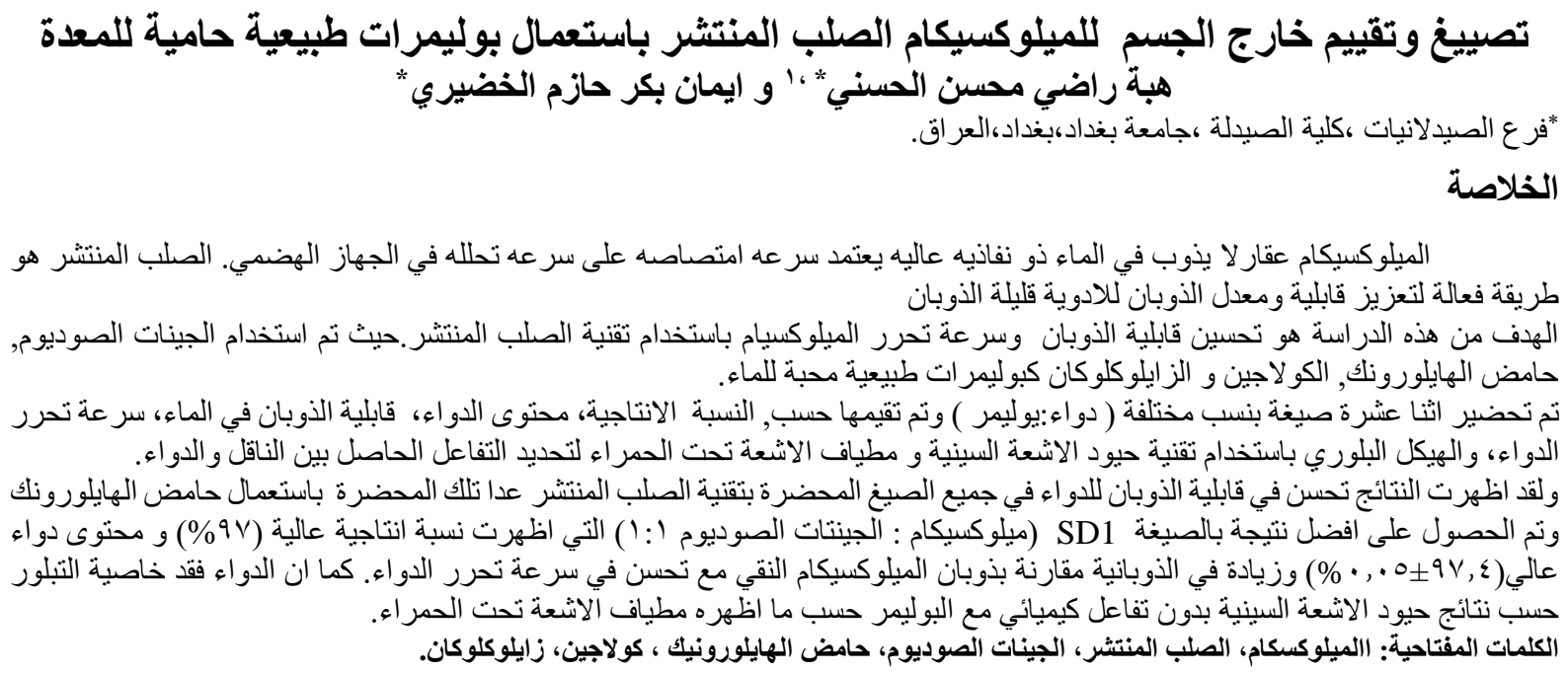

\section{Introduction}

Drug product solubility can be defined as being both quantitative and qualitative. The concept of quantitative solubility is the number of gram of solute particles required to make a saturated solution at certain temperature. While qualitative solubility is defined as where two phases are mixed together to form a homogeneous solution ${ }^{(1)}$.

It is one of the essential parameters for achieving desired drug concentration in systemic circulation for the desired pharmacological response. Low aqueous solubility is the main problem associated with the development of formulations of new chemical entities. Solubility is a major challenge for formulation scientist. Any drug to be absorbed must be present in the form of solution at the site of absorption ${ }^{(2)}$.

Solid dispersion (SD) is one formulation strategy used to improve the bioavailability of compounds with poor solubility. It can be defined as a pharmaceutical form in which the drug is dispersed in a biologically inert matrix, generally to improve the oral bioavailability of the drug by improving its dissolution rate in aqueous media ${ }^{(3)}$.

${ }^{1}$ Corresponding author E-mail: hiba.radi91@gmail.com

Received: 23/8/2020

Accepted: 21/ 11/2020

Iraqi Journal of Pharmaceutical Science 
Natural polymers have been used in different applications due to their desirable characteristics, such as abundant availability, biodegradability, and renewability.

These polymers are known to produce less toxic effects when compared with synthetic polymers and they versatile areas of their applications makes them attractive for research and development to make them suitable for different applications in food and pharmaceutical ${ }^{(4)}$.

Many natural polymers were used as carriers in the preparation of SD to enhance the dissolution rate of drug as they are easily soluble in water ${ }^{(5)}$.

Natural polymers such as collagen, alginates, hyaluronic acid xyloglucan are commonly used in wound healing because they have beneficial properties for this function ${ }^{(6)}$.

Collagen is a complex protein; the biodegradable properties of collagen are of critical importance in the natural process of healing wounds. Collagen prompts the formation of fibroblasts and accelerates endothelial cell migration contact with infected tissue ${ }^{(7)}$.

Hyaluronic acid (HA) is a natural linear polysaccharide ${ }^{(8)}$. It is used in medicine for the treatment of osteoarthritis, eye and plastic surgery, tissue engineering. It is also used for drug delivery ${ }^{(9,10)}$.

Sodium alginate (SA) is the sodium salt of alginic acid a polyanionic polysaccharides of microbial origin It can protect the GIT lining due to the gel formation depending on the $\mathrm{pH}$ of the environment. In the stomach, water penetrates the dosage form, initiating surface hydration, leading to the formation of a gel layer, which may protect the stomach lining ${ }^{(11,12)}$.

The tamarind seed xyloglucan $(\mathrm{XG})$ is a natural neutral hemicellulose (hydrophilic polysaccharide), characterized by film-forming protective barrier properties, it is a safe nonpharmacological alternative for the management of different diseases such as gastrointestinal disorders ${ }^{(13,14)}$.

Meloxicam (MLX) chemically known as " 4-Hydroxy-2-methyl-N-(5methyl-2-thiazolyl)-2H1,2-benzothiazine-3-carboxamide 1,1-dioxide" , $\mathrm{C}_{14} \mathrm{H}_{13} \mathrm{~N}_{3} \mathrm{O}_{4} \mathrm{~S}_{2}$ as empirical name, molecular weight of 351.4. MLX has structural formula described in Figure 1.

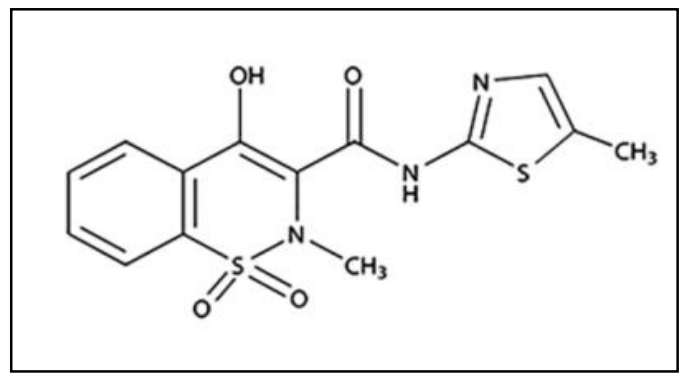

Figure 1.Structural formula of $\operatorname{MLX}^{(15)}$
Meloxicam is a non-steroidal anti inflammatory drug of the oxicam class that acts by inhibiting the prostaglandin synthesis, by inhibiting prostaglandin synthetize (cyclooxygenase (COX) ) mainly COX-2 isoform of cyclooxygenase thereby exerting anti-inflammatory, anti-exudative, analgesic and antipyretic effects, it is also emerging as a promising drug for the treatment of Alzheimer's disease and cancer. A primary advantage of the oxicam family of drugs is their long half-life which permits it to be used once daily (16). The drug is practically insoluble in water; ${ }^{(17)}$. It has Log $\mathrm{P}$ (octanol/water) equals 3.43 and dissociation constants $\mathrm{pKa}$ of 1.1 and 4.2 and its absolute bioavailability is about $89 \%{ }^{(15)}$.

MLX may result in gastrointestinal toxicity and bleeding can occur at any time during use and without signs of warning. Elderly patients are at greater risk of serious gastrointestinal problems ${ }^{(16)}$.

The aim of this research was to prepare solid dispersion of MLX using sodium alginate, hyaluronic acid, collagen and xyloglucan as natural polymers with expected gastro-protective effect and study their effect on the solubility and dissolution rate of MLX.

\section{Materials and Methods Materials}

Meloxicam (MLX), hyaluronic acid (HA), collagen, xyloglucan (XG) were purchased from Hangzhou, Hyperchem. China. Sodium alginate (SA) was purchased from HiMedia laboratories, India

Method

Preparation of solid dispersion of $M L X$

Solid dispersion of MLX was prepared by a solvent evaporation method using different natural polymers SA, Collagen, $\mathrm{XG}$ and $\mathrm{HA}$ as shown in Table 1 . The polymers were dispersed in $20 \mathrm{ml}$ of $20 \% \mathrm{v} / \mathrm{v}$ of methanol separately by utilizing a magnetic stirrer, until a clear solution was obtained, MLX was then added and stirring was continued for 10 min. Different drug: polymer ratio (w:w) were utilized depending on the viscosity of the polymeric solution. After that, the solvent was allowed to evaporate using oven at a temperature of $40^{\circ} \mathrm{C}$ for 24 hours. The resultant dried mass was pulverized and sieved through sieve no. 20 to get uniform particle size then stored in a desiccator for further investigations ${ }^{(18,19)}$. 
Table1. Composition of different SD formulas of MLX

\begin{tabular}{|c|c|c|c|c|c||}
\hline $\begin{array}{c}\text { Formula } \\
\text { Code }\end{array}$ & $\begin{array}{c}\text { MLX } \\
(\mathbf{g})\end{array}$ & $\begin{array}{c}\text { SA } \\
(\mathbf{g})\end{array}$ & $\begin{array}{c}\text { Collagen } \\
(\mathbf{g})\end{array}$ & $\begin{array}{c}\text { XG } \\
(\mathbf{g})\end{array}$ & $\begin{array}{c}\text { HA } \\
(\mathbf{g})\end{array}$ \\
\hline SD1 & $\mathbf{1}$ & $\mathbf{1}$ & $\ldots$ & $\ldots$ & $\ldots$ \\
\hline SD2 & $\mathbf{1}$ & $\mathbf{2}$ & $\ldots$ & $\ldots$ & $\ldots$ \\
\hline SD3 & $\mathbf{1}$ & $\mathbf{3}$ & $\ldots$ & $\ldots$ & $\ldots$ \\
\hline SD4 & 1 & $\ldots$ & $\mathbf{0 . 5}$ & $\ldots$ & $\ldots$ \\
\hline SD5 & 1 & $\ldots$ & 1 & $\ldots$ & $\ldots$ \\
\hline SD6 & 1 & $\ldots$ & 2 & $\ldots$ & $\ldots$ \\
\hline SD7 & 1 & $\ldots$ & $\ldots$ & $\mathbf{0 . 5}$ & $\ldots$ \\
\hline SD8 & 1 & $\ldots$ & $\ldots$ & $\mathbf{1}$ & $\ldots$ \\
\hline SD9 & 1 & $\ldots$ & $\ldots$ & $\ldots$ & $\mathbf{0 . 5}$ \\
\hline SD10 & 1 & $\ldots$ & $\ldots$ & $\ldots$ & 1 \\
\hline SD11 & 1 & $\ldots$ & $\ldots$ & $\ldots$ & 2 \\
\hline SD12 & 1 & $\ldots$ & $\ldots$ & $\ldots$ & $\ldots$ \\
\hline
\end{tabular}

\section{Preparation of physical mixture (PM)}

The PM was prepared by uniform mixing of drug and polymer in the same ratio as that of the best SD formula. The mixed powder was passed through a sieve no.20 to get uniformly sized particles

\section{Evaluation of SD of MLX \\ Determination of percentage yield (PY \%) of the prepared $S D$ of $M L X$}

The percentage yield for each type of SD was determined by measuring the ratio of the actual weight of the obtained SD on the theoretical weight of SD which was calculated using the equation below ${ }^{(20)}$.

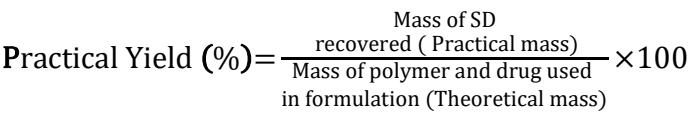

\section{Determination of drug content of the prepared $S D$} of $M L X$

A precisely weighed quantity of SD equivalent to $15 \mathrm{mg}$ of MLX was taken and dissolved in a $20 \mathrm{ml}$ of $0.1 \mathrm{~N} \mathrm{NaOH}$, with stirring for $10 \mathrm{~min}$, after that, the contents were filtered using a filter paper. Then after suitable dilution the solution was assayed for drug content using UV spectrophotometer by determining the absorbance at $363 \mathrm{~nm}$ using $0.1 \mathrm{~N} \mathrm{NaOH}$ as blank (21). The percentage of drug content in the SD was measured by using the following equation ${ }^{(22)}$.

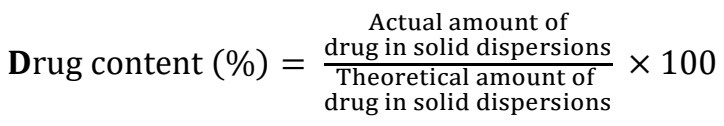

\section{Determination of saturation solubility}

An excess amount of MLX and SD were added to $10 \mathrm{ml}$ of distilled water separately, the samples were incubated in water bath shaker for 48 hr at $25{ }^{\circ} \mathrm{C}$. After that, the samples were removed from the shaker water bath. The solutions were filtered via a $0.45 \mu \mathrm{m}$ filter syringe and diluted when necessary. The concentration of MLX was analyzed by UV spectrophotometer at $362 \mathrm{~nm}$, which represents the solubility of MLX. The procedure was performed in triplicate ${ }^{(23)}$.

\section{In-vitro dissolution studies of pure MLX and SD of MLX}

In-vitro dissolution studies of pure MLX and SD were performed by placing an amount equivalent to $15 \mathrm{mg}$ MLX in $900 \mathrm{ml}$ phosphate buffer ( $\mathrm{pH}$ 7.5) as dissolution medium using USP type 2 apparatus for two hours. The temperature of the dissolution media was kept at $37 \pm 0.5{ }^{\circ} \mathrm{C}$, with an operating speed of $75 \mathrm{rpm}^{(24,25)}$.

Five milliliters were withdrawn and then replaced by fresh media of dissolution at regular time intervals, filtered and analyzed spectrophotometrically at $361 \mathrm{~nm}$. Solid dispersion formulas with highest solubility were subjected to this test. This test was performed in triplicate for all samples.

The results acquired from the dissolution studies were statistically validated using a similarity factor (f2). The f2 was used to consider similar dissolution profiles (equation below).

$$
\mathrm{f}_{2}=50 \times \log \left\{\left[1+\frac{1}{n} \sum_{t=1}^{n}\left|R_{t}-T_{t}\right|^{2}\right]^{-0.5} \times 100\right\}
$$

Where (n) is the number of dissolution time points. (Rt), (Tt) are the reference and test dissolution values at time $t$ respectively.

The two dissolution profiles consider similar when f2 values greater than $50(50-100)$; otherwise, the profiles are not similar ${ }^{(26)}$.

\section{Powder X-ray diffraction (PXRD)}

Powder X-Ray Diffraction was utilized to analyse the crystallinity of the pure MLX and selected formula. Measurement was performed under the following conditions: the target metals $\mathrm{Cu}$, filter $\mathrm{K} \alpha, 45 \mathrm{kV}$ voltage, $30 \mathrm{~mA}$ current. Samples 
scanned over a $2(\theta)$ range of $5-80^{\circ}$ at a step size of $0.02^{\circ}(27)$.

\section{Fourier Transforms Infrared Spectroscopy (FTIR)}

FTIR Spectroscopy of MLX, selected polymer, PM and the selected SD formula was performed to investigate drug-polymer intermolecular interaction. The samples were compressed with $\mathrm{KBr}$ and pressed in disk form (13 $\mathrm{mm}$ in diameter). The FTIR spectroscopy analyzed the disk from $4000-400 \mathrm{~cm}^{-1}(28)$.

\section{Results and Discussion}

\section{Percentage yield (PY \%) the prepared SD}

Calculation of the PY\% of the prepared formula is important to determine the efficiency of the preparation method. High PY was obtained from all the prepared SDs formulas ranged between (90.5$100 \%$ ) as shown in Table3. This relatively small amount of loss occurred due to some steps of preparation or sieving of the formula. This result indicated the suitability of the method (solvent evaporation method) with the used material for such preparations.

\section{Drug content of the prepared SD of MLX}

The results of drug content in all formulations, was found to be within $(91-104 \%) \mathrm{w}$ /w, which is consistent with USP requirements (90$105 \%)^{(29)}$. Suggesting no loss of MLX during the preparation and uniform distribution of MLX particles in all the prepared formulas. The results of drug content are shown in Table 2.

Table2. Percentage yield and drug content of SD.

\begin{tabular}{|l|l|l|l|l|l||}
\hline $\begin{array}{l}\text { Formula } \\
\text { Code }\end{array}$ & $\begin{array}{l}\text { Percentage } \\
\text { yield } \\
(\mathbf{P Y} \%)\end{array}$ & $\begin{array}{l}\text { Drug content } \mathbf{( w / w )} \\
(\boldsymbol{\%}) \\
(\mathbf{M e a n} \pm \mathbf{S T D})(\mathbf{n}=3)\end{array}$ & $\begin{array}{l}\text { Formula } \\
\text { Code }\end{array}$ & $\begin{array}{l}\text { Percentage } \\
\text { yield } \\
(\mathbf{P Y} \%)\end{array}$ & $\begin{array}{l}\text { Drug } \\
(\mathbf{w} / \mathbf{w})(\boldsymbol{\%}) \\
(\mathbf{M e a n} \pm \mathbf{S T D})(\mathbf{n}=\mathbf{3})\end{array}$ \\
\hline SD1 & 97 & $97.4 \pm 0.05$ & SD7 & 90.5 & $99.92 \pm 0.42$ \\
\hline SD2 & 91.98 & $97.47 \pm 0.12$ & SD8 & 95 & $104.07 \pm 0.06$ \\
\hline SD3 & 98.5 & $104.36 \pm 0.32$ & SD9 & 95 & $98 \pm 0.05$ \\
\hline SD4 & 92 & $96.79 \pm 0.3$ & SD10 & 97.5 & $92.1 \pm 0.1$ \\
\hline SD5 & 99.40 & $99.94 \pm 0.06$ & SD11 & 97 & $99.1 \pm 0.01$ \\
\hline SD6 & 99 & SD12 & 99 & $95.09 \pm 0.08$ \\
\hline
\end{tabular}

Saturation solubility of MLX SDs

Results of saturation solubility studies of

MLX SDs are shown in Table 3.

Table 3.The Saturation solubility of pure MLX and SDs formulas using different natural polymers with different Drug: Polymer ratio in distilled water at $25^{\circ} \mathrm{C}$

\begin{tabular}{||l|l|l|}
\hline \hline Formula Code & Polymer (drug : polymer ) ratio & $\begin{array}{l}\text { Saturation solubility mg/ml } \\
\text { Mean } \pm \text { STD (n=3) }\end{array}$ \\
\hline MLX & & $0.00981 \pm 0.001$ \\
\hline SD1 & SA (1:1) & $0.340 \pm 0.001$ \\
\hline SD2 & SA (1:2) & $0.351 \pm 0.06$ \\
\hline SD3 & SA (1:3) & $0.347 \pm 0.05$ \\
\hline SD4 & Collagen $(1: 0.5)$ & $0.0222 \pm 0.0005$ \\
\hline SD5 & Collagen $(1: 1)$ & $0.0663 \pm 0.025$ \\
\hline SD6 & Collagen $(1: 2)$ & $0.0401 \pm 0.016$ \\
\hline SD7 & XG (1:0.5) & $0.0228 \pm 0.0035$ \\
\hline SD8 & XG (1:1) & $0.0276 \pm 0.0018$ \\
\hline SD9 & XG (1:2) & $0.0276 \pm 0.003$ \\
\hline SD10 & H.A (1:0.5) & $0.0185 \pm 0.0009$ \\
\hline SD1 & H.A (1:1) & $0.0166 \pm 0.01$ \\
\hline SD12 & H.A (1:2) & $0.015 \pm 0.007$ \\
\hline
\end{tabular}

It was found that there was significant difference $(\mathrm{p}<0.05)$ between SA, Collagen, $X G$ in enhancing solubility of MLX. The solubility enhancing effect of the above polymers can be ranked in the following order $\mathrm{SA}>$ collagen $>\mathrm{XG}$, whereas no significant $(\mathrm{P}>0.05)$ enhancing in solubility was obtained by using HA

The above sequence may be explained to be due to different properties of the used polymers; SA has high hydrophilic property, and its particles are hydrated at a faster rate when the solid dispersion mixture comes into contact with water. Therefore, SA wetting effect may explain the improved solubility of MLX from solid dispersion even with the least amount as there was no significant difference $(\mathrm{P}>0.05)$ between the three different used ratios. This result may be attributed to the increase in the viscosity of the solution by increase in polymer concentration, which hinder further increase in solubility ${ }^{(30)}$.

The second polymer, collagen although it is insoluble polymer, it consists of three polypeptides chains: glycine, proline, and hydroxyproline, arranged as a triple helix, the hydrophilic groups $(-\mathrm{OH},-\mathrm{COOH}$, and $-\mathrm{NH})$ contained in these amino acids have the ability to 
absorb water which may enhance the wettability and hence solubility of MLX. When the collagen SDs formulas dispersed in water, these hydrophilic groups which located within the inner parts of the structure may not make contact with water, and consequently, this reduce the water absorption, therefore this polymer has lower solubility enhancing effect than SA ${ }^{(31,32)}$.

The solubility enhancing effect obtained by XG can be attributed to its water solubility that led to its application as a solubility enhancing polymer in preparation of SD. (33,34). This result is in agreement with that obtained by Babu et (35). Increasing the amount of XG up to1:2 (drug: polymer) did not show increase the solubility over that of 1:1 ratio which may be due to the formation of a viscous layer in the form of an aqueous solution that hinder the hydration of MLX particles ${ }^{(33)}$.

On the other hand, the no significant $(\mathrm{P}>0.05)$ enhancement in solubility of MLX by HA may be due to the formation of very viscous solution by large water soluble hyaluronic acid molecule event at low concentration ${ }^{(36)}$. This viscosity increased by increasing in polymer concentration, which could be linked to the increasing polymer chain entanglement and higher chances of hydrogen bonding at higher polymer concentration, resulted in further decrease in the solubility of MLX ${ }^{(37)}$.

\section{In-vitro dissolution studies}

In the present study, the SD1, SD2 and SD3 (prepared with S.A as a polymer with different ratio $1: 1,1: 2$ and $1: 3$, respectively) were selected to study the effect of drug: polymer ratio on the dissolution of MLX, since the highest solubility of MLX was obtained by these formulas.

Figure 2 demonstrates that all SD1, SD2 and SD3 have enhanced dissolution rate in phosphate buffer (pH7.5) in comparison to pure drug $(f 2=7.33),(f 2$ $=8.91)$ and $(f 2=11.50)$, respectively.

SD1 exhibited the highest the percent of MLX release by $(95 \%)$ after 30 minutes as compared with SD2 (84\%), SD3 (75\%) and pure MLX (2\%).

The enhanced dissolution of the drug from SDs can be attributed to reduced particle size of the drug within SDs, also it is assumed that the higher the wettability and dispersibility of a drug in a hydrophilic polymer, the better the chances of achieving an increase in drug dissolution profile $(6,38)$.

On the other hand, similar dissolution profile $(f 2=$ 62.03) was obtained by comparing SD1 to SD2, while dissimilar dissolution profile $(f 2=44.21)$ obtained by comparison of SD1 with SD3.

From the previous results, it was found that the increasing the amount of SA resulted in lowering the rate of release of MLX. This result can be explained to be due the formation of viscous layer with increased thickness that acted as a barrier for the dissolution medium thereby retarding the diffusion of drug from the SD causing retardation in the dissolution of the drug ${ }^{(39,40)}$. This result is in accordance with Noyes - Whitney equation which expresses the dissolution process as follow ${ }^{(41)}$ :

$$
\frac{d m}{d t}=A \frac{D}{d}(C s-C \mathrm{~b}) . . \mathrm{Eq}(4) .
$$

Where

$\mathrm{dm} / \mathrm{dt}=$ solute dissolution rate

$\mathrm{m}=$ mass of dissolved material

$\mathrm{t}=$ time

$A=$ surface area of the solute particle

$\mathrm{D}=$ diffusion coefficient, which is related, in part, to the viscosity of the solvent

$\mathrm{d}=$ thickness of the of the diffusion layer

$\mathrm{Cs}=$ particle surface (saturation) concentration

$\mathrm{Cb}=$ concentration in the bulk solvent/solution.

So decreasing $\mathrm{D}$ (due to increase viscosity) and increase $d$ resulted in decrease dissolution rate

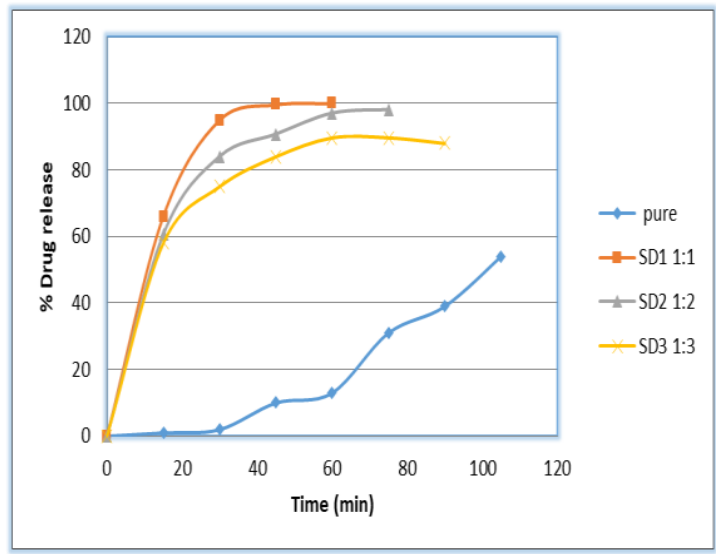

Figure (2). Effect of Drug: SA ratio of MLX- solid dispersion on the in-vitro dissolution profile of MLX in phosphate buffer pH 7.5 at $37^{\circ} \mathrm{C}$.

\section{Evaluation of the optimum formula Comparative dissolution study}

An improvement in the dissolution was obtained by SD1 and by PM in comparison with pure drug $(f 2=7.33, f 2=13.94$ respectively $)$ as shown in Figure 3, which can be ascribed to enhance drug wettability, by the hydrophilic property of SA. On the other hand, the enhanced dissolution obtained by SD1 compared to the PM $(f 2=35.69)$ can be explained to the efficiency of the solid dispersion technique that may cause particle size reduction and formation of amorphous form of drug, which required further investigation by XRD (42). 


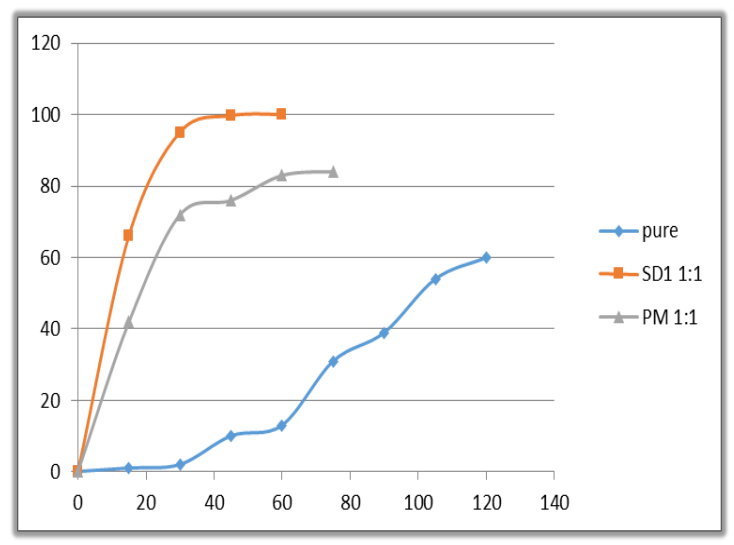

Figure 3. Comparative in-vitro dissolution profile of the pure MLX, SD1 and physical mixture of SD1 (PM) in phosphate buffer $(\mathrm{pH} 7.5)$ at $37 \pm 0.5$ ${ }^{\circ} \mathrm{C}$

\section{Powder X-ray diffraction (PXRD)}

The PXRD diffractogram of pure MLX, PM and SD1 are shown in Figure 4 respectively. The diffraction pattern of the pure MLX showed characteristic high intensity peaks at $6.06^{\circ}, 13.74^{\circ}$, $15.89^{\circ}, 19.32^{\circ}, 21.48^{\circ}, 21.55^{\circ}, 24.7^{\circ}$ and $26.57^{\circ}$, which indicates that the drug is present in the crystalline form. These values approach the values of the previous studies ${ }^{(43,44)}$.

Physical mixture's pattern showed the characteristic peaks of MLX with lower intensity compared to the pure drug. This result can be explained to be due to the dilution effect of the polymer. In contrast, further decrease of the characteristic peaks of MLX was observed with SD1, indicating that an amorphous form mostly exists in SD1 ${ }^{(45)}$.

This amorphous form may contribute to solubility improvement since this form is more easily soluble than the crystalline form.

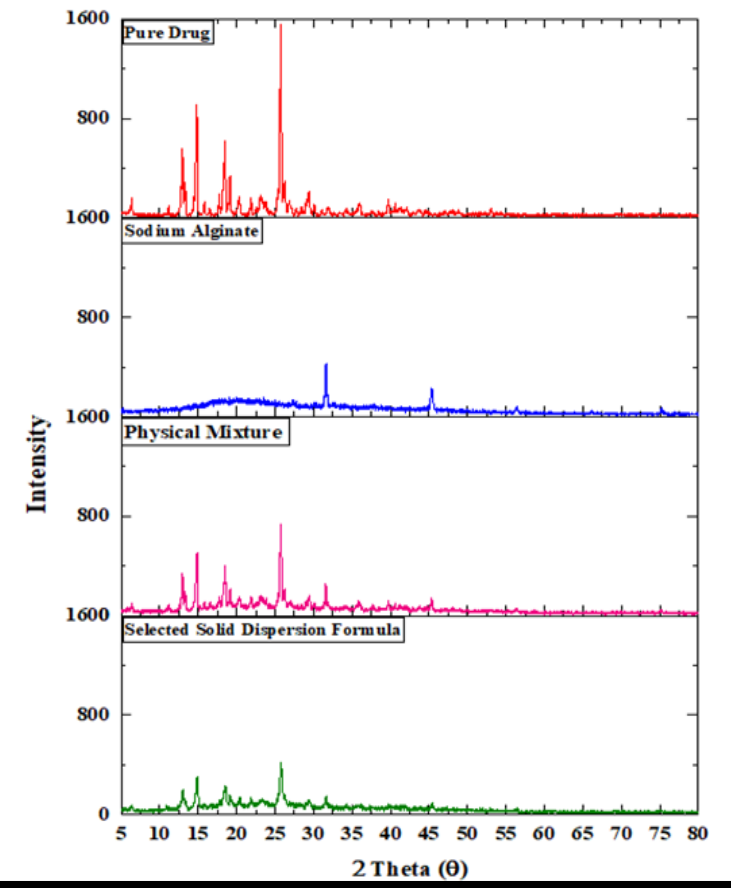

Figure 4. XRD diffractograms of MLX, SA, PM and SD1

\section{Fourier transform infrared (FTIR)}

The FTIR spectrum of pure MLX, SA, PM and SD1 are shown in Figures (5-8) respectively. The spectrum of pure MLX showed characteristic peaks at $3288 \mathrm{~cm}^{-1}$ (N-H stretching vibrations), 1620 $\mathrm{cm}^{-1}\left(\mathrm{C}=\mathrm{N}\right.$ stretching vibrations), $1159 \mathrm{~cm}^{-1}(\mathrm{~S}=\mathrm{O}$ stretching vibrations) respectively ${ }^{(28)}$. The obtained results were in accordance with the previous studies $(43,44)$

In the case of pure SA, a sharp broad absorption peak occurs at $3413 \mathrm{~cm}^{-1}$, referring to the presence of $-\mathrm{OH}$ groups bonded with hydrogen. The major SA absorption peaks occurring at 1603 and $1429 \mathrm{~cm}^{-}$ ${ }^{1}$ related to $\mathrm{COO}$ - groups, while the peak occurring at $2925 \mathrm{~cm}^{-1}$ is due to $\mathrm{C} \mathrm{H}$ stretching. SA's characteristic peak $(\mathrm{Na}-\mathrm{O})$ is shown at $849 \mathrm{~cm}^{-1}(28)$. These results were in agreement with previous studies ${ }^{(46,47) \text {. }}$

The spectra of PM Figure 7 and that of selected SD1 formula Figure 8 showed all the characteristic peaks of the drug, indicating that there was no chemical interaction between MLX and SA. The decreased intensity of the pecks in the above figures may be due to dilution effect of the polymer. 


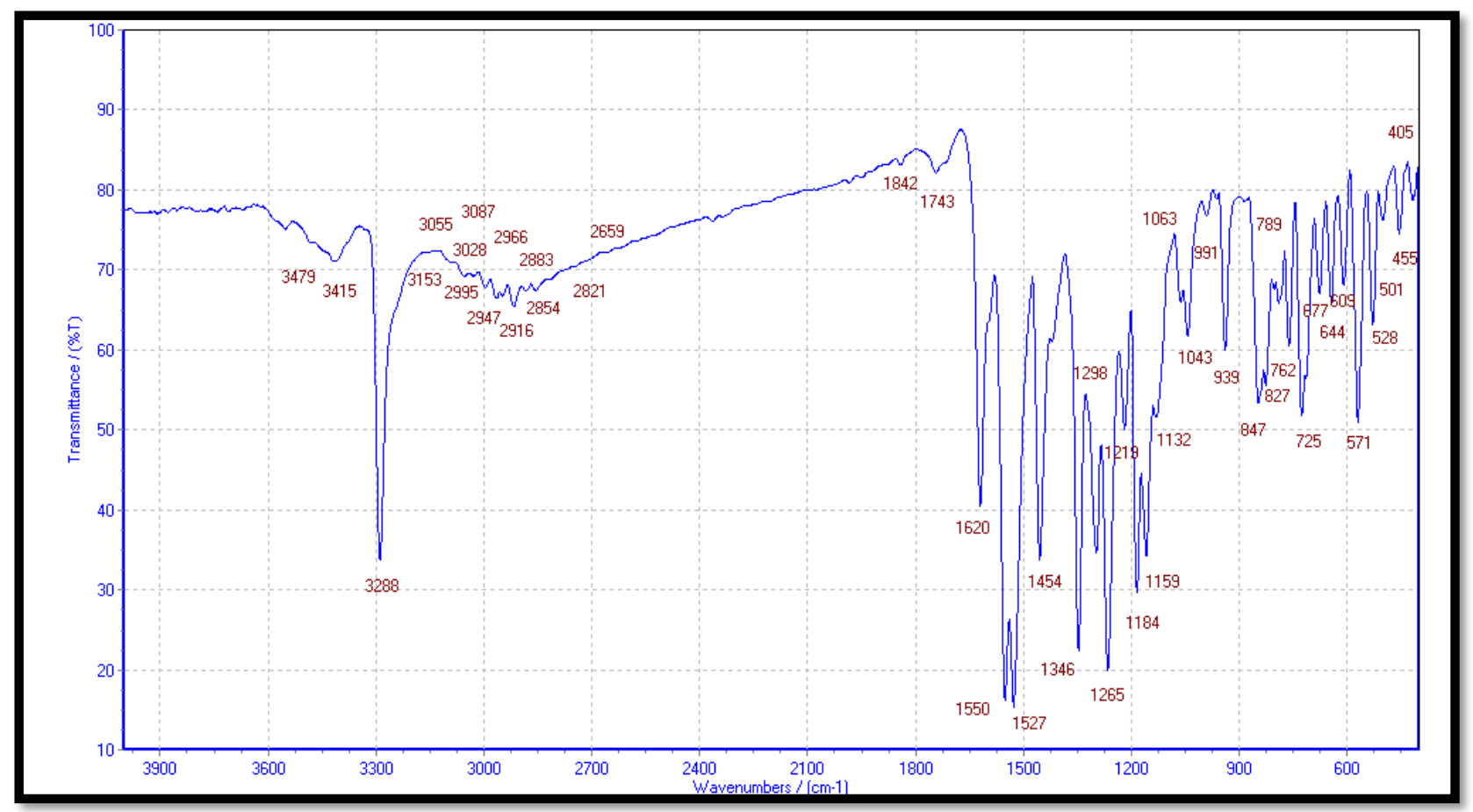

Figure 5.FTIR spectrum of MLX

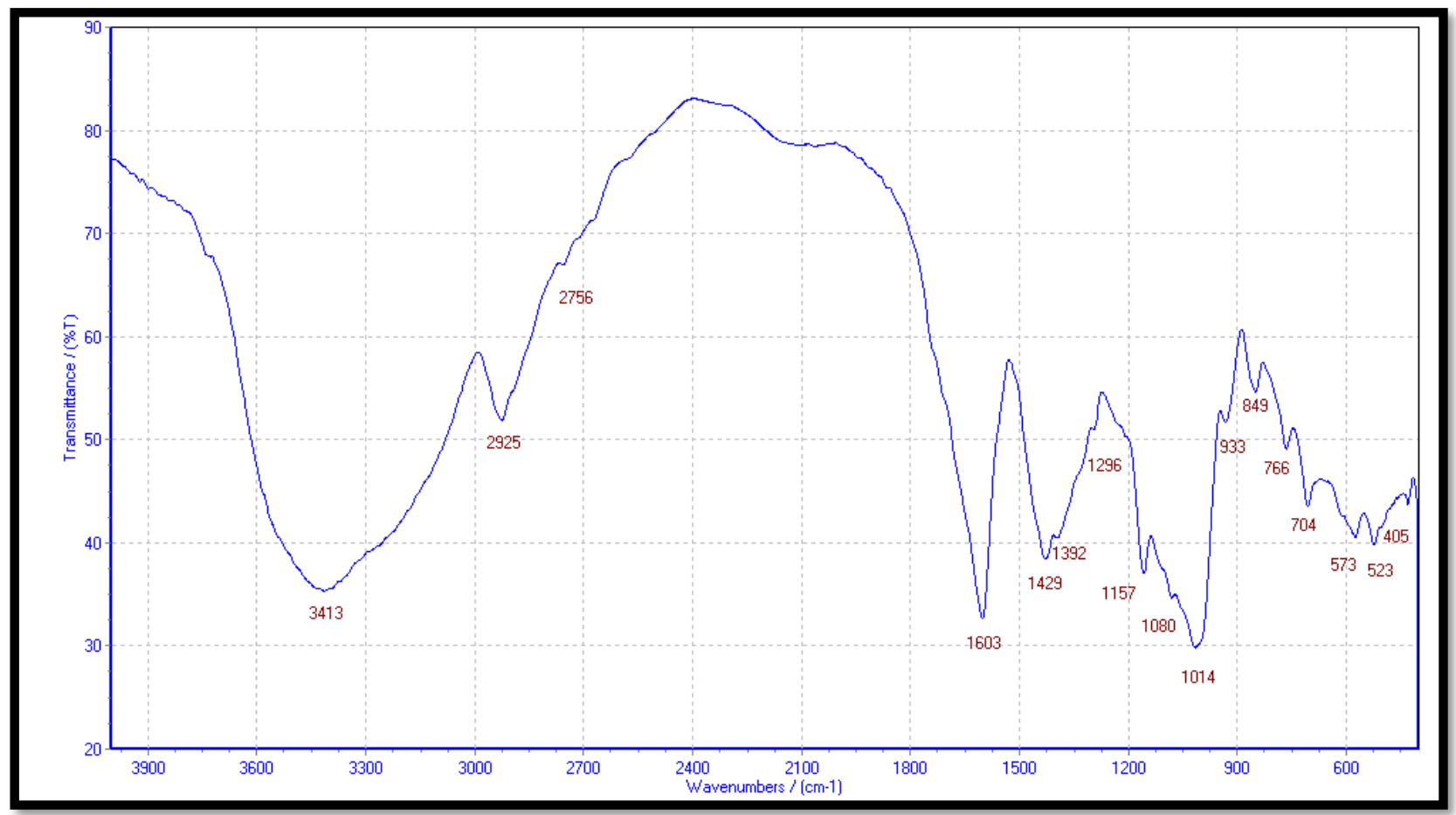

Figure 6. FTIR spectrum of SA 


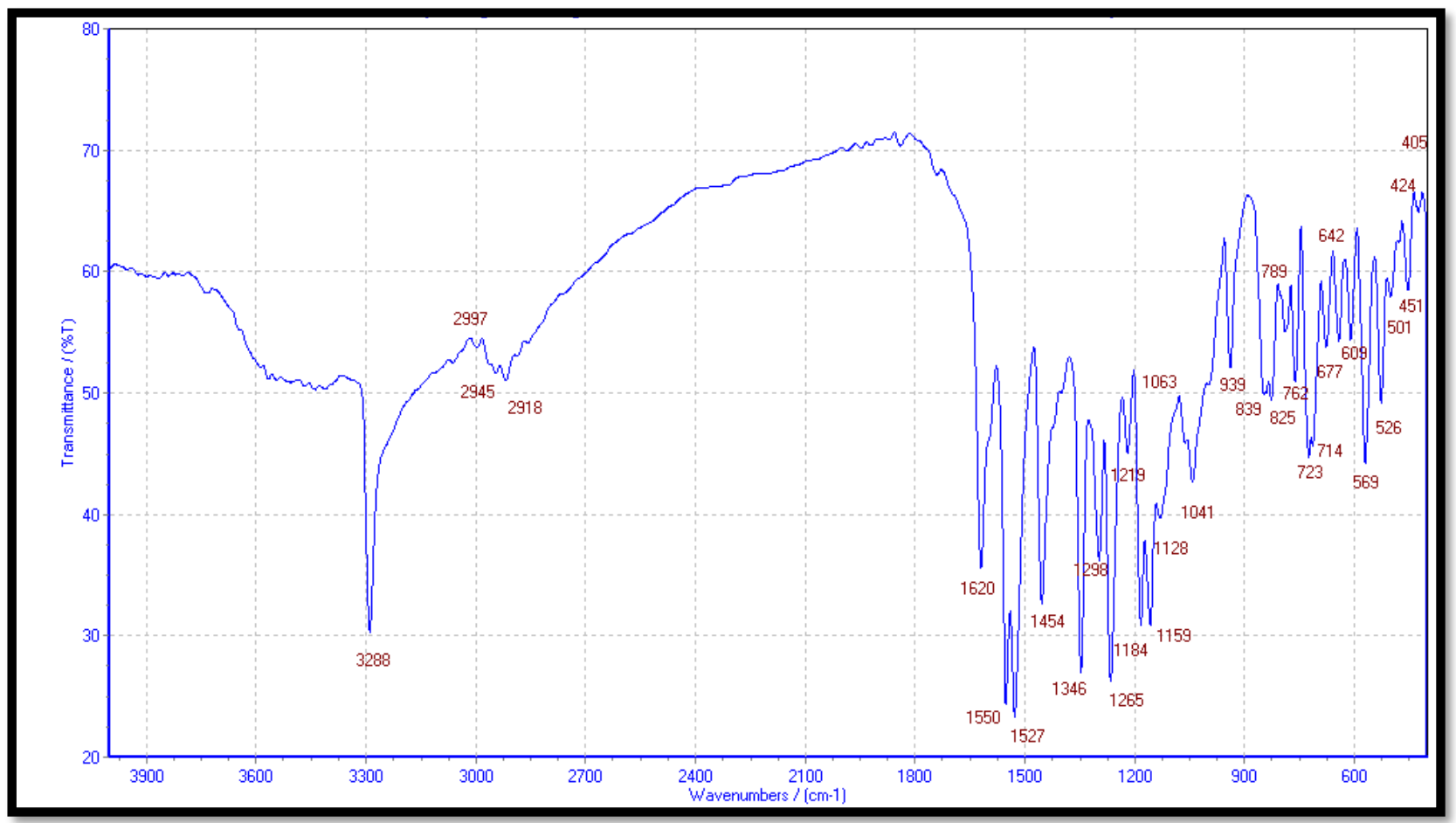

Figure 7. FTIR spectrum of PM

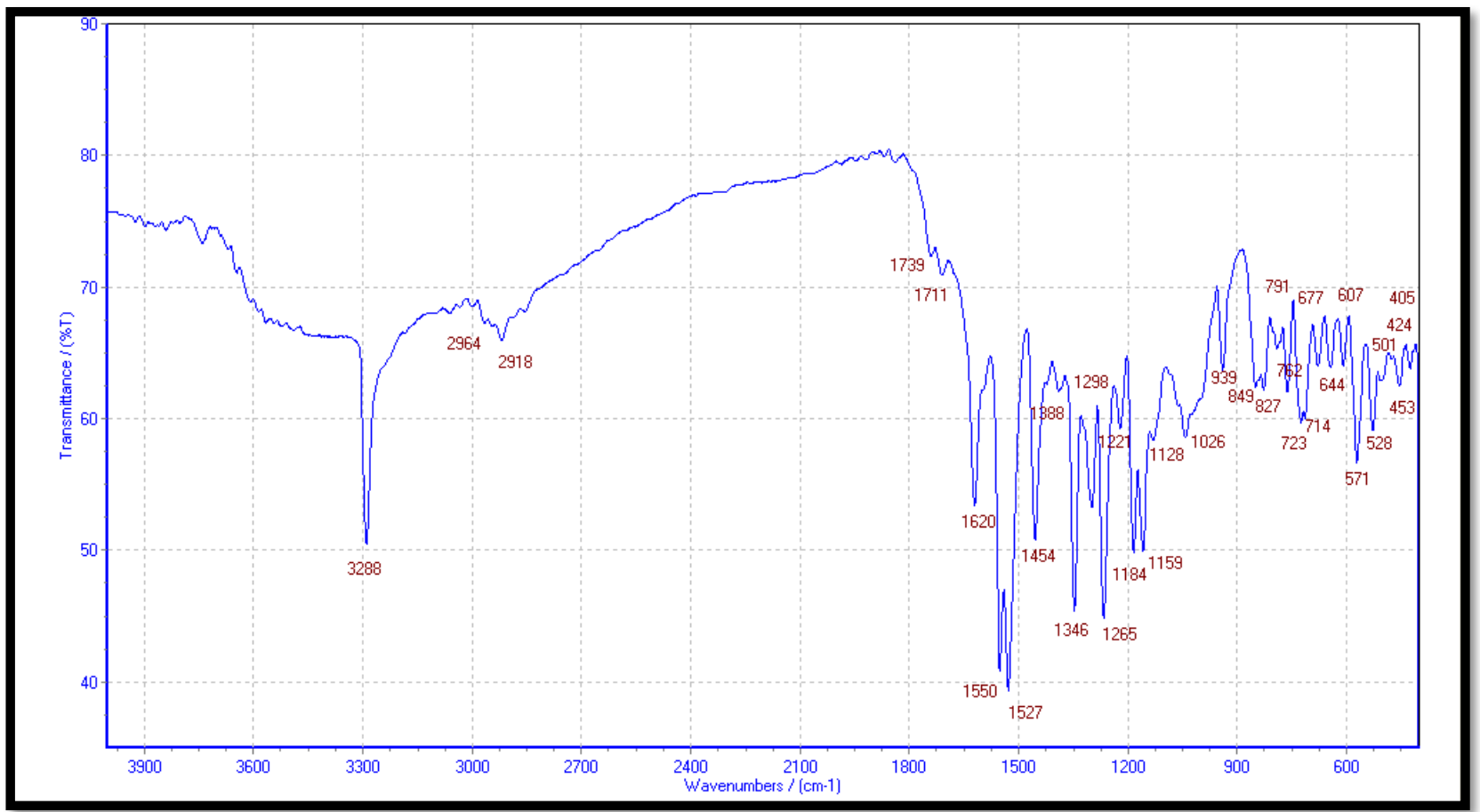

Figure 8. FTIR spectrum of SD1

\section{Conclusions}

An improvement in solubility and dissolution rate of MLX was obtained by preparing it as solid dispersion by solvent evaporation method using SA as a natural hydrophilic polymer in a ratio of 1:1. drug: polymer. This improvement was due to increased wettability and reduced crystallinity of the drug.

\section{Future work}

Clinical studies are required to confirm whether the sodium alginate protects the stomach lining from irritation due to the chronic use of MLX Acknowledgement

The authors are grateful to acknowledge the College of Pharmacy -University of Baghdad for 
providing the necessary facilities to carry out this study.

\section{References}

1. Patrick J. Sinco. Martin's physical pharmacy and pharmaceutical science. 6th ed. Lippincot Williams and wilkins 2011; P.182.

2. Karen D H, Prajapti P. H., Chaudhary J I. BCS Classification And Solubility Enhancement Techniques For BCS Class II And BCS Class IV Drugs. EJBPS. 2019; 6(1), 663-670.

3. Bikiaris D N. Solid dispersions. Part I: recent evolutions and future opportunities in manufacturing methods for dissolution rate enhancement of poorly water-soluble drugs. Expert Opin Drug Deliv. 2011; 8(11): 15011519.

4. Doppalapudi S, Katiyar S, Domb A.J, Khan S W. Biodegradable natural polymers. In: Puoci F. Advanced Polymers in Medicine. Switzerland: Springer; 2015, p. 33-66.

5. Shaikh Siraj N, Athar S H MD, Khan G J, Raza S, Ansari M A. Review on solid dispersion of poor water soluble drug by using natural polymers. The Pharma Innovation Journal 2019; 8(1): 631-636.

6. Olatunji O. Natural polymers industry techniques and applications. Switzerland: Springer; 2016, p.93-115.

7. Peng, X. S., Guo, C. L., Fan, Z. Q., Li, Y. L., Liu, W. E., Dai, Z., ... \& Zahou.Y.F. Preparation and Characterization of Capsaicin-Collagen Sponge. BJSTR,2019;16(5): 12353-12360.

8. Iannitti T, Lodi D, Palmieri B. Review article: Intra-articular injections for the treatment of osteoarthritis. Drugs in R \& D. 2011; 11(1):1327.

9. Becker L C, Bergfeld W F, Belsito D V, Klaassen C D, Marks J G , Shank R C, \& Andersen F A. Final report of the safety assessment of hyaluronic acid, potassium hyaluronate, and sodium hyaluronate. Int $\mathrm{J}$ Toxicol.2009; 28(4_suppl):65-67.

10. Khvostov M V, Tolstikova T G, Borisov S A, Dushkin A V. Application of natural polysaccharides in pharmaceutics. Russian Journal of Bioorganic Chemistry. 2019; 45(6):563-575.

11. Nahar K., Hossain M. K., Khan T. A. Alginate and its versatile application in drug delivery. $\mathrm{J}$. Pharm. Sci. \& Res. 2017; 9(5): 606-617.

12. Lee K. Y., Mooney D. J. Alginate: properties and biomedical applications. Progress in Polymer Science.2012;37(1): 106-126.

13. Pardeshi C V, Kulkarni A D, Belgamwar V S , Surana S J. Xyloglucan for drug delivery applications. In: Thomas S, Balakrishnan P, Sreekala M S. Fundamental Biomaterials: Polymers. :Woodhead Publishing; 2018, p . 143-169.
14. Piqué N, Gómez-Guillén M. D. C, Montero M. P. Xyloglucan, a plant polymer with barrier protective properties over the mucous membranes: an overview. Int. J. Mol. Sci..2018;19(3): 673.

15. Moffat A.C., Osselton M.D., Widdop B. Clarke's analysis of drugs and poisons. Electronic Edition Pharmaceutical Press, Great Britin.2005.

16. Tripathi KD. Esssential of medical pharmacology. 5th ed. New Delhi: Jaype Brothers Medical Publishers (P) Ltd; 2004: 327-39.

17. British Pharmacopoeia, 2009, London: Crown Inc.

18. Poovi G. Umamaheswari M, Sharmila S, Kumar S, Rajalakshmi A N. Development of domperidone solid dispersion powders using sodium alginate as carrier. Europ. J. Appl. Sci.2013; 5(2):36-42.

19. Delgado D R, Jouyban A, Martínez F. Solubility and preferential solvation of meloxicam in methanol+ water mixtures at 298.15 K. Journal of Molecular Liquids. 2014;197:368-373.

20. Kaza R, Raju Y P, R. Nagaraju. Dissolution enhancement of valsartan using natural polymers by solid dispersion technique.Der Pharmacia Lettre, 2013, 5 (2):126-134.

21. Basu S K, Mandal S. Spectrophotometric methods for the estimation of meloxicam in dosage forms. Asian J. Chem. 2009; 21(7): 5184-5188.

22. Soni L, Ansari M, Thakre N, Singh A, Bhowmick M, Rathi J. Development and invitro evaluation of furosemide solid dispersion using different water-soluble carriers. Int. J. Res. Dev. Pharm. L. Sci.2017;6(2):2571-2575.

23. Wei-Qin (Tony) Tong. Practical aspects of solubility determination in pharmaceutical preformulation. London:Springer;2007, p 138140.

24. Ghareeb M. M., Abdulrasool A. A., Hussein A. A., \& Noordin, M. I. Kneading technique for preparation of binary solid dispersion of meloxicam with poloxamer 188. Aaps Pharmscitech.2009;10(4), 1206-1215.

25. Vignaduzzo S E, Castellano P M, Kaufman T S. Development and validation of a dissolution test for meloxicam and pridinol mesylate from combined tablet formulation. Indian journal of pharmaceutical sciences.2010; 72(2):197-203.

26. Costa $P$, Lobo JM. Modeling and comparison of dissolution profiles. Eur j pharm sci.2001;13(2):123-33.

27. Fitriani L, Fadhila M. Preparation of Efavirenz - PVP K-30 Solid Dispersion by Spray Drying. RJPBCS. 2015; 6(925):925-930. 
28. Silverstein R M, Bassler G C. Spectrometric identification of organic compounds. $\mathrm{j}$ Chem. Educ. 1962;39(11):546.

29. The United State Pharmacopeia (USP) 41, NF36. Convention Inc. Rockville, MD. 2018.

30. Borba P. A. A., Pinotti M., de Campos C. E. M., Pezzini B. R., Stulzer H. K. Sodium alginate as a potential carrier in solid dispersion formulations to enhance dissolution rate and apparent water solubility of BCS II drugs. Carbohydrate polymers.2016; 137: 350-359.

31. Lukitowati F., Indrani, D. J. Water absorption of chitosan, collagen and chitosan/collagen blend membranes exposed to gamma-ray irradiation. IJPS. 2018;14(1): 57-66.

32. Kawamata H., Kuwaki S., Mishina T., Ikoma T., Tanaka, J., Nozaki R. Hierarchical viscosity of aqueous solution of tilapia scale collagen investigated via dielectric spectroscopy between $500 \mathrm{MHz}$ and $2.5 \mathrm{THz}$. Scientific reports.2017; 7:45398.

33. Piqué N, Gómez-Guillén M. D. C, Montero M. P. Xyloglucan, a plant polymer with barrier protective properties over the mucous membranes: an overview. Int. J. Mol. Sci..2018;19(3): 673 .

34. Satle, S. Agrawal. Solubility enhancement potential of tamarind seed polysaccharide as pharmaceutical excipient, Int. J. Curr. Pharm. Res.4 (2012) 67-73.

35. Babu GV, Gowrisankar V, Himasankar $\mathrm{K}$, Murthy KV. Studies on applicability of tamarind kernel powder as a carrier in the dissolution enhancement of poorly water soluble drug celecoxib. Boll Chim Farm. 2003; 142(2): 76-82.

36. B.M Caruta. Polymeric Materials: New Research book. New York: Nova science.2005.

37. Alkufi H K, Kassab Hanan J. Formulation and evaluation of sustained release sumatriptan mucoadhesive intranasal in-situ gel. Iraqi $\mathbf{J}$ Pharm Sci. 2019;28(2):95-104.

38. Handa U, Sarohak .Research and development of diazepam solid dispersion powder using natural polymers. Int J App Pharm.2018; 10(5):,220-225..
39. Srikrishna T., S. Sudheer, S. Srividya, V. Meghana Sai Kumar, B. Jonathan Wilson, Prasanth B , Raj C P .Study of effect of sodium alginate and calcium carbonate composition difference on in situ gelling gastroretentive amoxicillin liquid formulation. J. Chem. Pharm. Res. 2016; 8(5):736-745.

40. Manjanna K. M., Rajesh K. S., Shivakumar B. Formulation and Optimization of Natural Polysaccharide Hydrogel Microbeads of Aceclofenac Sodium for Oral Controlled Drug Delivery.American Journal of Medical Sciences and Medicine. 2013; 1(1):5-17.

41. Kar A., Essental of biopharmaceutics and pharmcokinetiks-E.book . 2922; p78.

42. Pathan D, Memon S, Siddique A. Enhancement of In-Vitro Dissolution Efficiency of Cefixime Trihydrate Using Natural Polymer by Solid Dispersion Technique. Curr. Pharm. Res. 2020;10(4): 3907-3918.

43. Kumar S. G. V., Mishra D. N.Preparation, characterization and in vitro dissolution studies of solid dispersion of Meloxicam with PEG 6000. Pharma.Society of Jap.2006;126(8):657664.

44. Dias R. J., Ranjan S., Mali K. K. Ghorpade V. S., Havaldar V D. Liquisolid compacts of meloxicam: in-vitro and in-vivo evaluation. EPJ.2017; 16:112-120

45. Abdulqader AA, Al-khedairy EBH. Formulation and evaluation of fast dissolving tablets of taste-masked ondansetron hydrochloride by solid dispersion. Iraqi J Pharm Sci .2017;26(1).50- 60.

46. Manjula B, Varaprasad K, Sadiku R, Raju K M. Preparation and Characterization of Sodium Alginate-Based Hydrogels and Their In Vitro Release Studies. Adv Polym Technol. 2013; 32(2):21340.

47. Kuzmanović M., Božanić D. K., Milivojević,D., Ćulafić D. M., Stanković,S., Ballesteros C., \& Gonzalez-Benito J. Sodiumalginate biopolymer as a template for the synthesis of nontoxic red emitting Mn 2+-doped CdS nanoparticles. RSC advances .2017;7(84) :53422 -53432.

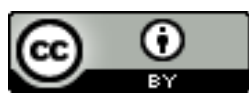

Baghdad Iraqi Journal Pharmaceutical Sciences by bijps is licensed under a Creative Commons Attribution $\underline{4.0}$ International License. Copyrights@ 2015 College of Pharmacy - University of Baghdad. 